\title{
Osteoporotic fracture risk in menopausal women
}

with obesity

Popovic-Pejicic Snjezana ${ }^{1}$, Aksentic Vera ${ }^{2}$

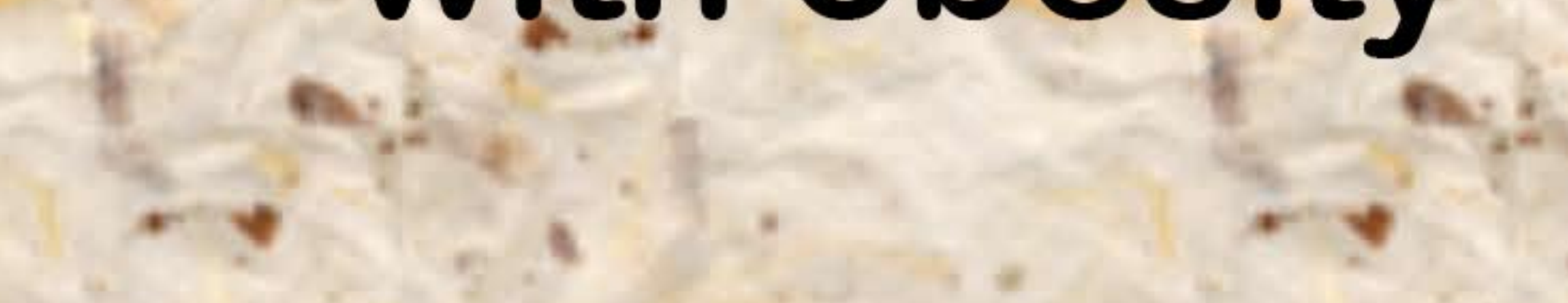

1.Center for diabetes et endocrinology, University hospital, Clinical center, Banja Lukka ,Republic of Srpska, Bosnia and Herzegovina 2. Institute for Physical Medicine and rehabilitation „Dr Miroslav Zotović „Banja Luka, Republic of Srpska, Bosnia and Herzegovina

\section{Introduction and objectives}

Osteoporosis is a metabolic disease that is characterised by low mineral bone density (BMD) and increased risk of fractures Wight loss reduced BMD and increased risk of hip fractures, while it reduces in a weight gain. Osteoporosis fracture risk and body mass index (BMI) correlate more frequently denied in recent studies. The aim of this study was to examine relationship between BMI and BMD in a group of postmenopausal women .

\section{Material and Methods}

The study involved 100 postmenopusal women, aged 46 to 70 years $(59,086,07)$. BMD was determined by DXA method (dual energy X-ray absorptiometry) by Lunar Prodigy Advance Unit.BMD was measured at lumbal spine and both hips. BMI values were correlated with total T score values of the lumbal spine and both hips, as well as total T score values of spine and hip.

\section{Results}

\begin{tabular}{|l|l|l|l|l|}
\hline & Age & Height & Weight & BMI \\
\hline Meanvalue & 59.08 & 161.29 & 73.64 & 28.27 \\
\hline $\begin{array}{l}\text { Standard } \\
\text { deviation }\end{array}$ & 6.07 & 6.11 & 11.98 & 4.12 \\
\hline Minimal & 46 & 147 & 52 & 21.08 \\
\hline Maximal & 70 & 173 & 119 & 42.67 \\
\hline
\end{tabular}

Table 1. Basic anthropometric parameters

\begin{tabular}{|l|l|l|}
\hline & Spine t_score & hip t_score \\
\hline Meanvalues & -2.19 & -1.11 \\
\hline Standard deviation & 1.25 & 0.95 \\
\hline Minimal & -5.5 & -3.7 \\
\hline Maximal & 1.8 & 1.7 \\
\hline
\end{tabular}

Table 2. Measured values BMD of Spine and Hip

Median lumbal spine T score was $-2,19$ SD $\pm 1,25$, and hip T score $-1,11$ SD $\pm 0,95$.

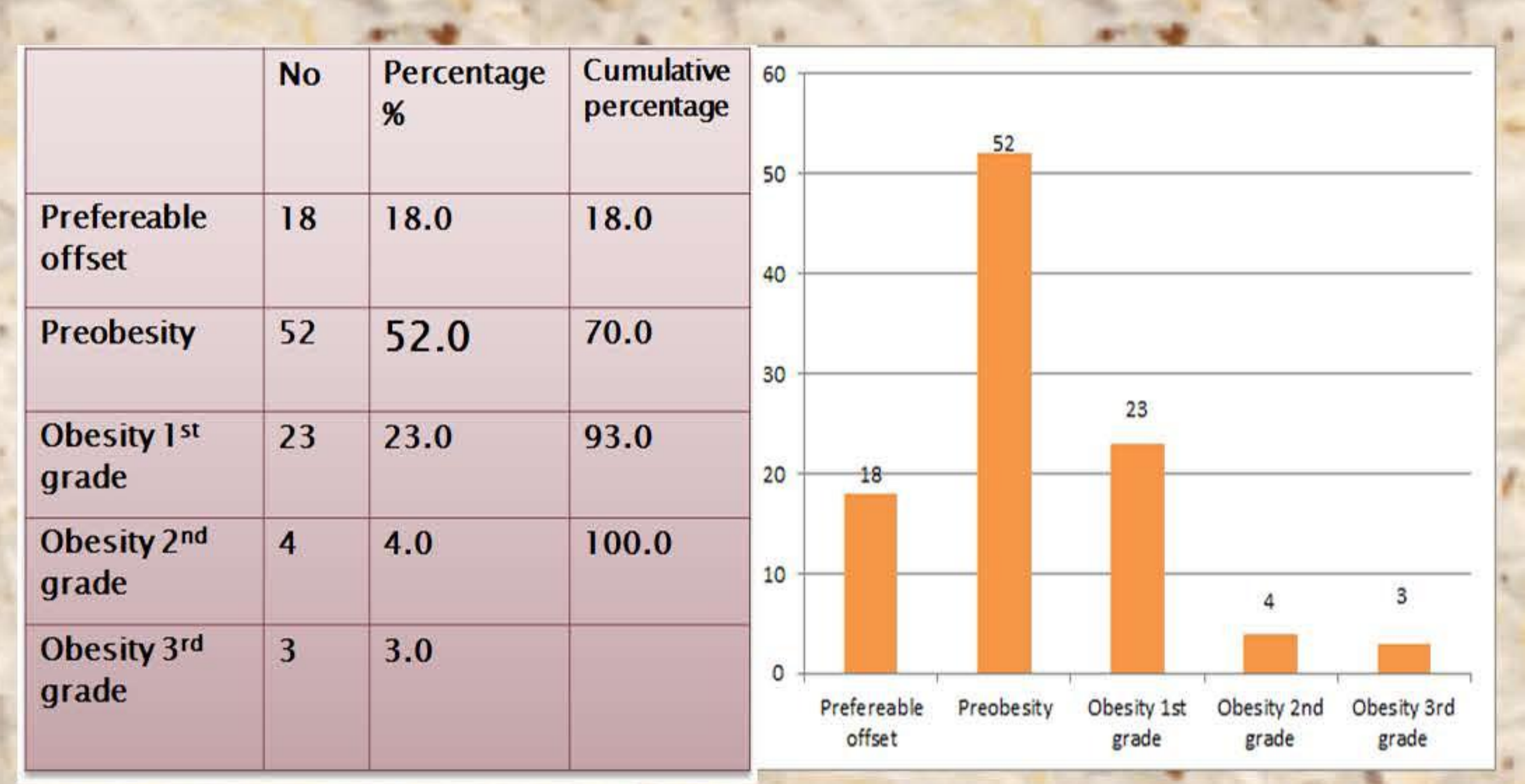

Table 3. Figure 1. Classification of subjects respondent to BMI

Results have shown that BMI was normal in $18 \%$ subjects 11 st grade obesity was faund in $52 \%, 2$ nd grade obesity in $23 \%, 3$ rd grade obesity in $7 \%$ of subjects . Median BMI value was found in $28,27 \pm 4,12$. (2.
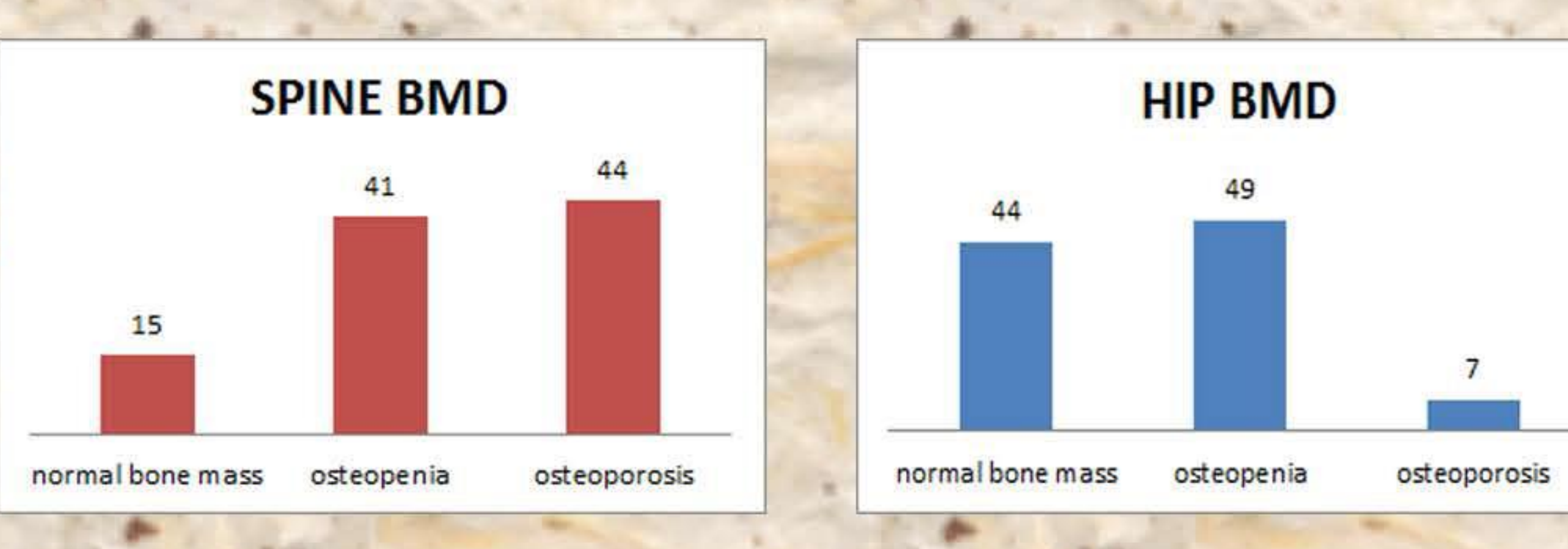

Figure 2. Classification of subjects respondent to BMD of Spine and Hip

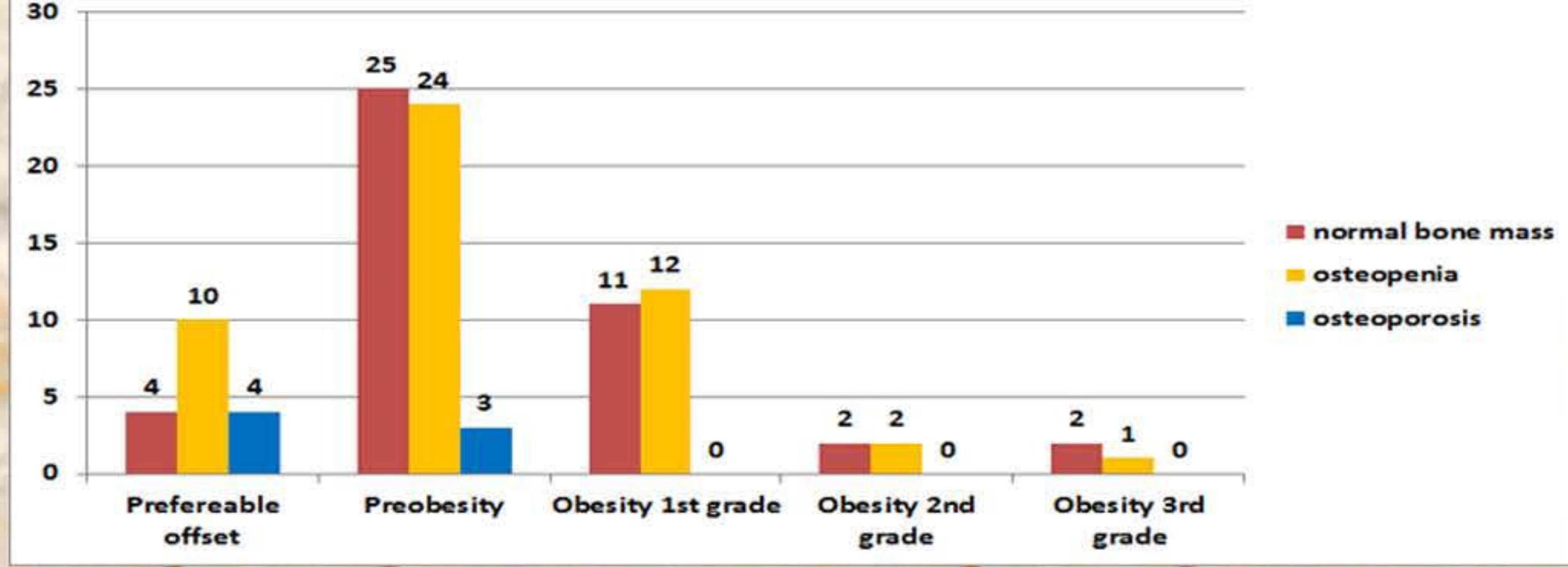

Figure 3. Comparative review BMI and hip BMD of subjects (Correlation significans $p<0.01$

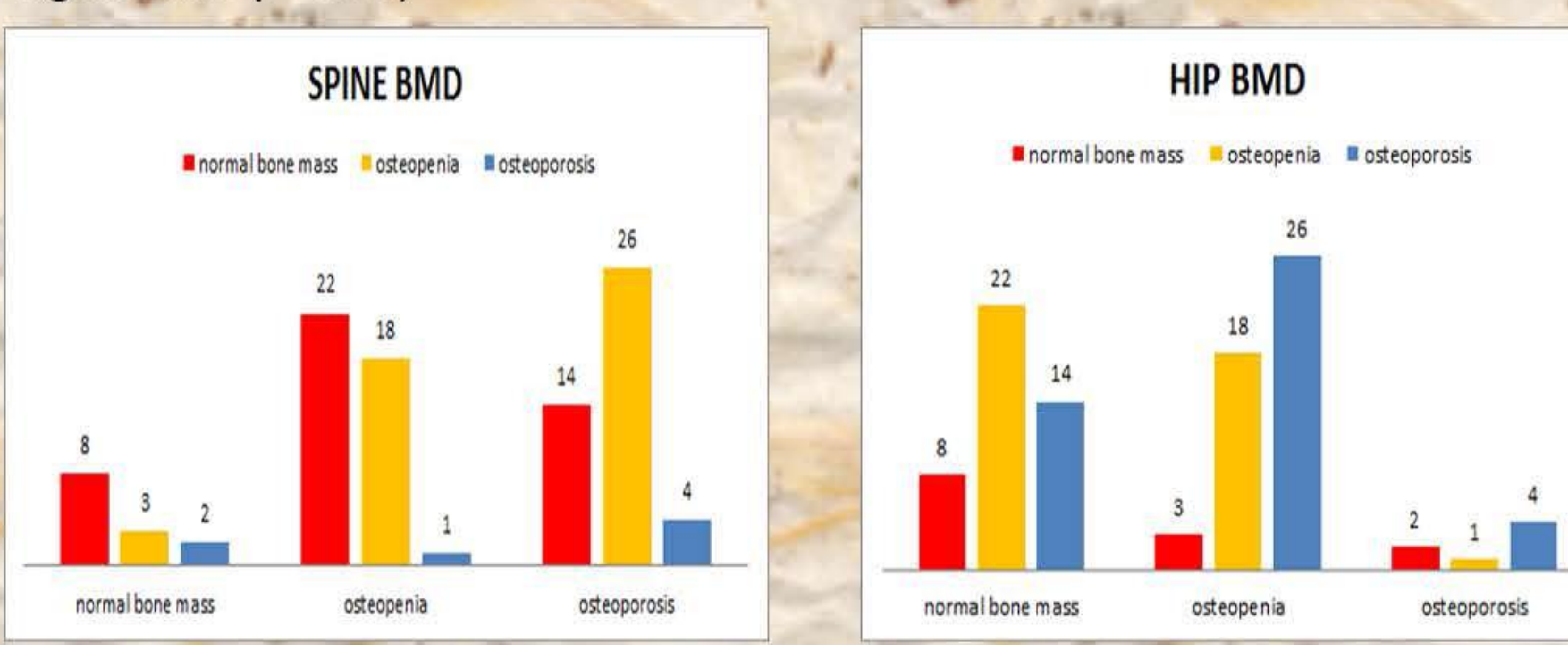

Figure 4. Classification of subjects respondent to BMD of Spine and Hip A statisticaly significant positive correlation was found between BMI and BMD of hip $(r=0.01)$, whereas between BMI and BMD of lumbal spine there was no.There was , statisticaly significa

\section{Conclusion}

In postmenopausal women BMI is more important predictor of hip BMD as compared to spine BMD

BMD of hip is increased with increase of BMI in postmenopausal women , what indicates that incidence of fracture of the hip decrease in women with obesity. metabolisam in spinat region.

\section{Literature}

.Campstone JE et al Obesity Is Not Protective against Fracture in

11, Buckwalter JA, Glimcher MJ, Cooper RR, Recker R. Bone biology. I:

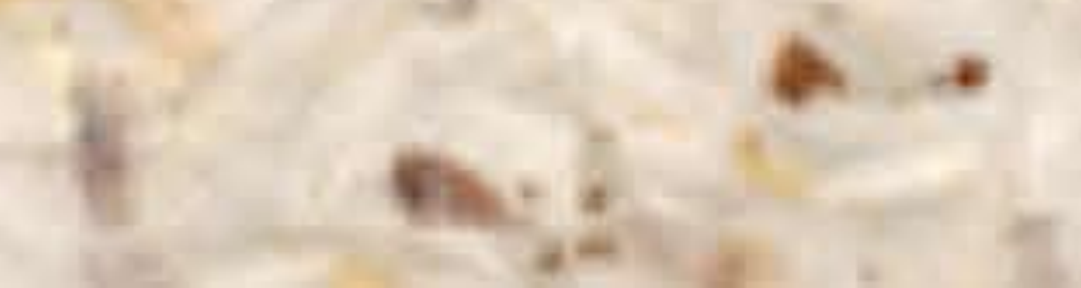

